\title{
RESPONSE THE COEFFICIENT OF PERFORMANCE MODELS FOR EVALUATION OF DIFFUSION ABSORPTION REFRIGERATION SYSTEM
}

\author{
Darwesh, M. ${ }^{1}$ and Atef M. Elsbaay ${ }^{2}$
}

\begin{abstract}
Three mathematical models were used to determine the coefficient of performance COP of the diffusion absorption refrigeration system DAR. These models give different results of COP because it depends upon various scientific bases. Therefore, in this study used the three models to compare between the values of COP. The first model from viewpoint of temperature thermodynamic ideal cycle, the second model using mass flow rate thermodynamic and the last model employing the cooling capacity of refrigerator. The highest value of COP by (model 1) was 1.26 while the lowest value was 0.77. Model 2 gave 0.671 as highest value and the lowest value was 0.475 , respectively. The highest value of COP by (model 3) was 0.155 while the lowest value was 0106. The exponential function behavior showed the relation between the generator temperature $(T g)$ and the circulation ratio(f) which can be described by the equation $f$ $=629.52 e^{-0.01937 g}, R^{2}=1$.The statistical indicators to select the actual COP indicated to the majority of values for three models by harmonic mean (HM) were $1.118,0.567$ and 0.124 , respectively. The study concluded that using second model is the best way to use for judgment of cycle performance because it depend upon the temperatures of refrigeration cycle parts and mass flow rate of working fluids in each part of this cycle.
\end{abstract}

\section{INTRODUCTION}


efrigeration is the process of cooling bodies or fluids to reduce temperatures lower than those variables in the surroundings at a particular time and place. The refrigeration covers a vast zone of applications, namely food and food processing, and air conditioning.

${ }^{1}$ Assoc. Prof. Agric. Eng. Dept., Faculty of Agric,Tanta University, Egypt. Email: rmdarwish@yahoo.com

1 Assoc. Prof. Agric. Eng. Dept., Faculty of Agric, Kafrelsheikh University, Egypt. E-mail: atef.ahmed@agr.kfs.edu.eg 
Generally, artificial refrigeration systems can be classified into two divisons such as vapor compression cooling system (use of mechanical compressor) and vapor absorption cooling system (use of thermal compressor-gas-fired or solar driven). Vapor compression systems for general cooling clean out great degrees of power generated by the burn of fossil fuels. Consequently, in Egypt these types of refrigeration can consume more electrical energy, this mean that more variable cost resulting in refrigeration requirements, particularly the large size of refrigerator and long period of cooling conservation. The sucking instruments have various features like saving the climate and the nature, this kind of refrigerating machine does not utilize Chlorofluorocarbons $\left(\mathrm{CFC}_{\mathrm{s}}\right)$ fluids, which affect the ozone layer. (Kang et al. 2000). The major characteristic of the DAR system is the use of a passive gas to supply a low potential atmospheric pressure in the evaporator and a solution bubble-pump coupled to the generator with a view to employ the calorific input capacity to lead the yielding circulation. Despite the coefficient of performance (COP) had a lower values when compared it to the vapor compression cycle, absorption refrigeration systems are hopeful for using inexpensive waste energy from industrial processes, geothermal energy, solar energy (Matta et al. 2017). The showing of a diffusion absorption refrigeration system is depending on the different system parts, which are interconnected by a few circulation loops. Many researchers studied, developed, evaluated and employed. Mazouz et al. (2014) examined a trade absorption fridge to set its performance with varied operating situations and founded a theoretical simulation model in steady state mode, for various DAR system forms. Ersoz et al. (2015) investigated experimentally the effect of three different generator heat inputs $(62,80$ and $115 \mathrm{~W})$ on the energy performance of the DAR. Agostini et al. (2016) presented a thermo dynamical model of a VonPlaten diffusion absorption refrigeration cycle for electronic power implentations. They validated their results by comparison for obtainable information in the literature for the classical water-ammonia-helium cycle for commercial absorption refrigerators. Their experimental conditions were high ambient temperature without compressor, for passive components losses of about $500 \mathrm{~W}$; with a compact and low cost solution. 
As such, the absorption refrigeration technology displays powerful potential for use in rustic socities in promoting zones, where crop and vaccine supply- chain administration call low cost, handed out cooling solutions. McCarney et al. (2016). Acuña et al. (2016) reported that laterally a renewed utility has been shown in absorption refrigeration technology for coupling with a wide range of heat exportes inclusive solar collectors. Ben Iffa et al. (2017) analyzed the energy of different absorption refrigerating methods working with several refrigerants. In addition, they focused on both agreeable COP and low operating generator temperature. Their results showed that the COP values against respectively the evaporator temperature, the temperature of condensation and the generator temperature. From the previous presentation indicated that the DAR system is a promising method in refrigeration processing particular in difficult cases. These critical cases can goaled in rural areas which suffering the fluctuations of electrical energy that lead to destroy vapor compression system. Furthermore, using this type of refrigeration can decrease pollution because it employs friendly environmental refrigerants. In addition, some engineering uses need the refrigeration unit such as: hydroponics system, vaccine preservations and fish storage where DAR can employs with these uses. Finally, this type can use any source of thermal energy to be operated it. Therefore, the main objective of this present study is to determine the values of COP by different models from viewpoints of: temperature thermodynamic, mass flow rate thermodynamic and cooling capacity In addition, calculates the energy requirements of these systems.

\section{MATERIALS AND METHODS}

The experiments were carried out during June 2018 in small village, Gharbia governorate located at $\left(30.95^{\circ} \mathrm{N}\right.$ and $\left.31.09^{\circ} \mathrm{E}\right)$. To evaluate performance of diffusion absorption refrigeration system. The operation of vapor refrigeration systems is based on the electricity, especially if these systems are used as a commercial refrigerators. Among the sources to produce, electricity in Egypt is burning the fuel. The considering the question of fuel demand and depletion of fossil fuels. Meanwhile, the operation of absorption refrigeration systems depend on the low grade heat to produce cooling effect. Therefore, using absorption refrigeration 
systems represent an alternative way of conventional compression refrigeration system. One of the types of absorption refrigeration system is the diffusion absorption refrigeration system (DAR).

In the DAR system the inert gas uses to provide a low partial pressure in the evaporator to allow the working fluid to circulate it throughout the refrigeration cycle. The traditional system utilizes ammonia as the refrigerant, water as the absorbent, and hydrogen as the inert gas. A DAR system is explained in Fig. (1)., in the generator unit, the refrigerant-rich solution is heated by any source (1-2) forming vapour bubbles that are elevated through the bubble pipe with a little magnitude of liquid (2-3,4). Ammonia refrigerant is districted from water absorbent in the rectifier (5) which flows down wards in the sol heat exchanger and is then sent to absorber (8). The ammonia vapour takes to the condenser where it condenses (6-7) emissioning heat to the environments.

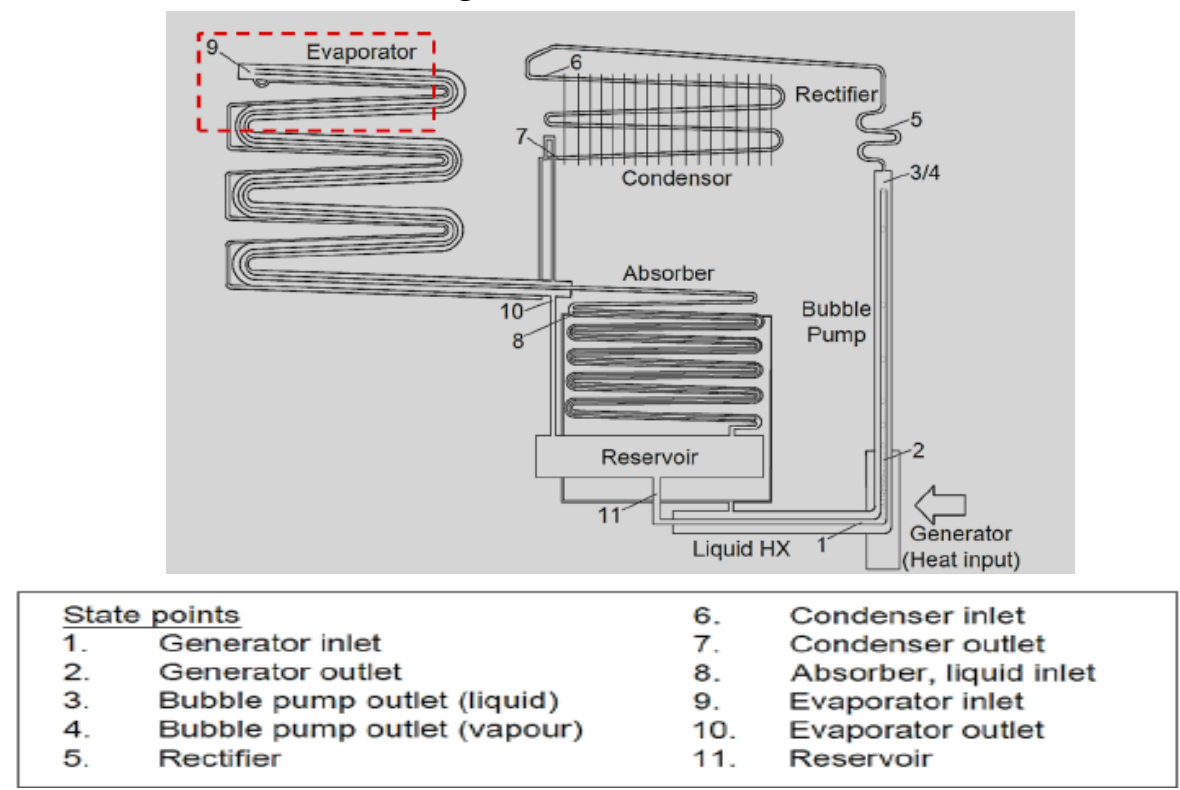

Fig. 1. A schematic diagram of the DAR system used in the present work with key state points by (Najjaran et al., 2017)

The resulting liquid is pre-cooled in the gas heat exchanger on its way to the evaporator, which is loaded with inert gas (hydrogen). Partial pressure drops and low-temperature evaporation beings (9-10), producing the refrigeration effect. The refrigerant vapour then enters the absorber where 
the refrigerant is hold by the absorbent, releasing heat to the surroundings. The inert gas is not absorbed and, being less dense the refrigerant, rises back to the evaporator in the gas heat exchanger. Fig.2, also shows the schematic diagram of the diffusion absorption refrigeration cycle to indicate the heat input to the system and the heat rejected from the system and describes the pathway of working fluid to produce refrigeration effect. The temperature sensors attached with data logger put at state pointes that indicated in Fig.1. The performance of DAR system is the main goal of studying this system to judge the effectiveness of this system for different applications. Generally, the scientific expression for the performance of the refrigeration systems is coefficient of performance (COP). Nevertheless, to calculate this performance should be covered the three different ways from viewpoints of temperature thermodynamic, mass flow rate thermodynamic and cooling capacity.



Fig.2. A schematic diagram of DAR system to indicate the heat input and heat rejected from the system by (Srikhirin et al., 2001)

\section{1-Maximum COP of ideal absorption refrigeration systems}

Model 1

In case of a single stage compression refrigeration system operating between constant evaporator (Te) and condenser (TC) temperatures, the maximum possible COP is given by Carnot COP (Mungan, 2017):

$$
\mathrm{COP}_{\text {carnot }}=\frac{T_{e}}{T_{c}-T_{e}}
$$

The assumption of heat rejection that at the absorber and condenser takes place at the same external heat sink temperature (condenser and absorber 
temperatures, To), then a vapour absorption refrigeration system operates between three temparture grades $\mathrm{Tg}$, To and Te. The ultimate possible COP of a refrigeration system operating between three temperature levels that can be obtained by applying the first and second laws of thermodynamics to the system. From the first law of thermodynamics:

$$
\mathrm{Qe}+\mathrm{Qg}-\mathrm{Qc}+\mathrm{a}+\mathrm{WP}=0
$$

Where: Qc+a is the heat transferred from the absorber and condenser of the absorption system at temperature (To) and WP is the work input to the solution pump.

From the second law of thermodynamics according to Keçeciler et al. (2000):

$$
\Delta \text { Stotal }=\Delta \text { Ssys }+\Delta \text { Ssurr } \geq 0
$$

Where: $\Delta$ Stotal is the total entropy change, which is equal to the sum of entropy change of the system $\Delta$ Ssys and entropy change of the surroundings $\Delta$ Ssurr. Since the refrigeration system works in a sealed cycle, the entropy change of the working fluid of the system undergoing the cycle is zero, i.e., $\Delta$ Ssys $=0$. The entropy change of the surroundings is given by:

$$
\Delta_{\text {surr }}=-\frac{Q_{e}}{T_{e}}-\frac{Q_{g}}{T_{g}}+\frac{Q_{a+c}}{T_{o}} \geq 0
$$

Substituting the expression for first law of thermodynamics in the above equation:

$$
\begin{array}{cc}
Q_{g} & Q_{q} \\
{\left[\frac{T_{g}-T_{o}}{T_{g}}\right] \geq\left[\frac{T_{o-} T_{e}}{T_{e}}\right]}
\end{array}
$$

Neglecting solution pump work, WP, the COP of VARS is given by:

$$
\mathrm{COP}=\frac{Q_{e}}{Q_{g}} \leq\left[\frac{T_{e}}{T_{o}-T_{e}}\right]\left[\frac{T_{g-} T_{o}}{T_{g}}\right]
$$

An ideal vapour absorption refrigeration system is totally reversible (i.e., both internally and externally reversible), for a completely reversible system to total entropy change (system +surroundings) is zero according 
to second law, hence from a ideal VARS $\Delta \mathrm{S}$ total.rev $=0 \Rightarrow \Delta \mathrm{S}$ surr.rev $=0$. Hence:

$$
\Delta S_{\text {surr, }}, r e v=-\frac{Q_{e}}{T_{e}}-\frac{Q_{g}}{T_{g}}+\frac{Q_{a+c}}{T_{o}}=0
$$

Hence combining the first and second law and neglecting pump work, the maximum possible COP of an ideal VARS system is given by:

$$
C O P_{\text {idealVARS }}=\frac{Q_{e}}{Q_{g}}=\left[\frac{T_{e}}{T_{o}-T_{e}}\right]\left[\frac{T_{g-} T_{o}}{T_{g}}\right]
$$

Thus, the ideal COP is only a function of operating temperatures similar to Carnot system. It can be seen from the above expression that the ideal COP of VARS system is equal to the product of efficiency of a Carnot heat engine operating between $\mathrm{Tg}$ and $\mathrm{To}$ and $\mathrm{COP}$ of a Carnot refrigeration system operating between $\mathrm{To}$ and $\mathrm{Te}$, i.e.,

$$
\begin{array}{r}
C O P_{\text {idealVARS }}=\frac{Q_{e}}{Q_{g}}=\left[\frac{T_{e}}{T_{o}-T_{e}}\right]\left[\frac{T_{g-} T_{o}}{T_{g}}\right] \\
=C O P_{\text {Carnot }} \cdot \eta_{\text {Carnot }}
\end{array}
$$

\section{Model 2}

The thermodynamic equations from view point of mass flow rate for working fluids of DAR refrigeration circuit by Kumar and Das (2015), and Fig. 1 indicates the paths of working fluids which equations illustrated it. The generator and bubble pump took a heat from any source cause increasing of total enthalpy of ammonia-water solution. Therefore, the thermal energy supplied at the generator:

$$
\mathrm{Qg}=Q_{g}=\dot{m}_{3} h_{3}+\dot{m}_{4} h_{4}-\dot{m}_{1} h_{1}
$$

Where: $\mathrm{m}$ mass flow rate in $\mathrm{kg} / \mathrm{s}$ and $\mathrm{h}$ is specific enthalpy in $\mathrm{J} / \mathrm{kg}$. The subscript numbers indicate the position of the fluid in DAR refrigeration circuit. It is supposed that with sufficient insulation, heat losses in the generator and bubble pump are negligible. Therefore, the specific enthalpy of the saturated liquid $h_{3}$ and vapour $h_{4}$ and is calculated by assuming that $\mathrm{T}_{2}=\mathrm{T}_{3}=\mathrm{T}_{4}$.

The liquid refrigerant flow-rate $\dot{m}_{6}=\dot{m}_{7}=\dot{m}_{9}$ proceeding to the evaporator is equal to the that leaving the condenser,. The energy balance 
for the evaporator considers both the pre-cooling and evaporation processes, and also the mass-flows of refrigerant and inert gas:

$$
Q_{e}=\dot{m}_{9}\left(h_{10}-h_{7}\right)+\dot{m}_{i g}\left(h_{10, i g}-h_{8, i g}\right)
$$

Where: ig is inert gas (hydrogen)

The mass flow rate and specific enthalpy determinate using $\mathrm{NH}_{3}$ tables calculator by MegaWatSoft programmed. The calculator gave the properties if it took the pressure and temperature. While, the hydrogen properties are also estimated by hydrogen properties calculator.

\section{Model 3}

The amount of generator and evaporator heat should be calculated to determine the COP.The heat of generator in electrical refrigeration calculated as follows:

$$
\text { Qtotal }=\mathrm{P} \tau
$$

Where: $\mathrm{Q}$ total $=$ is the total energy required in $\mathrm{kJ} /$ day, $\mathrm{P}=$ is the electric heater power in Watt, $\tau=$ is the time of operation of the electric heater over $24 \mathrm{~h}$ in second

According to Kassem et al . (1993), the effective cooling produced can be calculated. It is necessary first to measure the maximum and minimum temperatures of load which is cooled potato and Qev can be calculated from:

$$
\text { Qev }=\mathrm{W} * \text { CPair } *(\text { Tmax }- \text { Tmin })
$$

Where: $\mathrm{Qev}=$ The total cooling effect $(\mathrm{kW}), \mathrm{W}=$ mass of air to be cooled $(\mathrm{kg}), \mathrm{CPair}=$ specific heat of air at constant pressure $(\mathrm{kJ} / \mathrm{kg}), \mathrm{Tmax}=$ initial temperature of the load (air) at which the cooling process starts $\left({ }^{\circ} \mathrm{C}\right)$ and $\mathrm{Tmin}=$ load of minimum temperature that can be reached $\left({ }^{\circ} \mathrm{C}\right)$.

Mansori et al. (2015) reported that the heat loss from cabinet (cooling capacity) is equal to the heat from evaporator as the energy balance by the following equation:

$$
\mathrm{Q}_{\text {loss }}=\mathrm{Q}_{\text {evap }}
$$

The heat loss from cabinet can be estimated from the following equation:

$$
\left.\mathrm{Q}_{\text {loss }}=(\mathrm{UA})_{\mathrm{cab}}\left(\mathrm{T}_{\mathrm{int}}-\mathrm{T}_{\mathrm{amb}}\right)\right)
$$

Where: (UA) cab is the overall heat transfer coefficient of the refrigerated room which is evaluated using a calibration method of heat electricity as a 
source of heat. The electrical heater connected to a power controller that has the ability to change the power. The following equation can be used to calculate the (UA)cab

$$
(\mathrm{UA})_{\mathrm{cab}}=\mathrm{Q}_{\text {loss }} /\left(\mathrm{T}_{\mathrm{int}}-\mathrm{T}_{\mathrm{amb}}\right)
$$

Where: Tint is internal temperature of cabinet $\left({ }^{\circ} \mathrm{C}\right)$ and Tamb is ambient temperature. This value equal $0.554 \mathrm{~W} / \mathrm{K}$.

Babu and Yadav (2015) defined the circulation ratio as the ratio of the mass flow rate of the strong solution entering $\left(\dot{m}_{11}\right)$ the generator to the mass flow rate of refrigerant $\left(\dot{m}_{2}\right)$ as revealed in Fig.1, the equation can be written:

$$
f=\frac{\dot{m}_{11}}{\dot{m}_{2}}
$$

Circulation ratio $(f)$ is defined as the ratio between the mass flow rate of the strong solution and the mass flow rate of the refrigerant. Therefore, it showed the times of circulation of working fluids in the refrigeration cycles. This indicator as a function of generator and evaporator temperatures, which had the direct effect on the mass flow rate of working fluids.

\section{The statistical indicators to select the actual COP}

To select the actual COP values among the three equations should be used the statistical indicators. The Pythagorean means (harmonic, arithmetic and geometric).

Harmonic mean (HM) can be calculated by the following equation:

$$
H M=\frac{n}{\sum\left(\frac{1}{x_{i}}\right)}
$$

Where $\mathrm{n}$ is the number of the values in a dataset and $\mathrm{xi}$ is the point in dataset.

Geometric mean can be estimated from the following equation:

$$
G M=\sqrt[n]{x_{1} . x_{2} \ldots \ldots x_{n}}
$$

Arithemtic mean (AM) can be estimated from the following equation:

$$
A M=\frac{x_{1}+x_{2}+\ldots .+x_{n}}{n}
$$




\section{RESULTS AND DISCUSSION}

The COP can be calculated from three equations based on three different theoretical approaches. Therefore, the following data will analyze the performance of these equations from view point of thermodynamic and heat transfer and comparison between them. The seven positions of thermostat settings by timer in the refrigerator were selected to know the thermal characteristics during the operation the first position of thermostat gave $16,14{ }^{\circ} \mathrm{C}$ without and with load, respectively. In addition, the minimum temperatures were $6,4{ }^{\circ} \mathrm{C}$ at the seventh position of thermostat without and with load, respectively. This result means that the range of inside air temperature in the refrigerating unit ranged from 4 to $10{ }^{\circ} \mathrm{C}$ at the third to the seventh thermostat position settings. This range corresponds to the recommended storage temperature for different agricultural crops which can be stored according to Rastovsky (1987). The range of the obtained temperature is considered evidence that the absorption refrigeration system has the capability to be used for potato storage according to Darwesh et al. (2010). Table1 represents the relationship between the generator, outside and inside temperatures for the higher outside air temperature than other days during storage period. Fig.3. indicates the hourly average outside air temperature was 36.50 and $21.20{ }^{\circ} \mathrm{C}$ during day and nighttime, the temperature inside refrigerating unit increased from sunrise until it $1 \mathrm{AM}$.

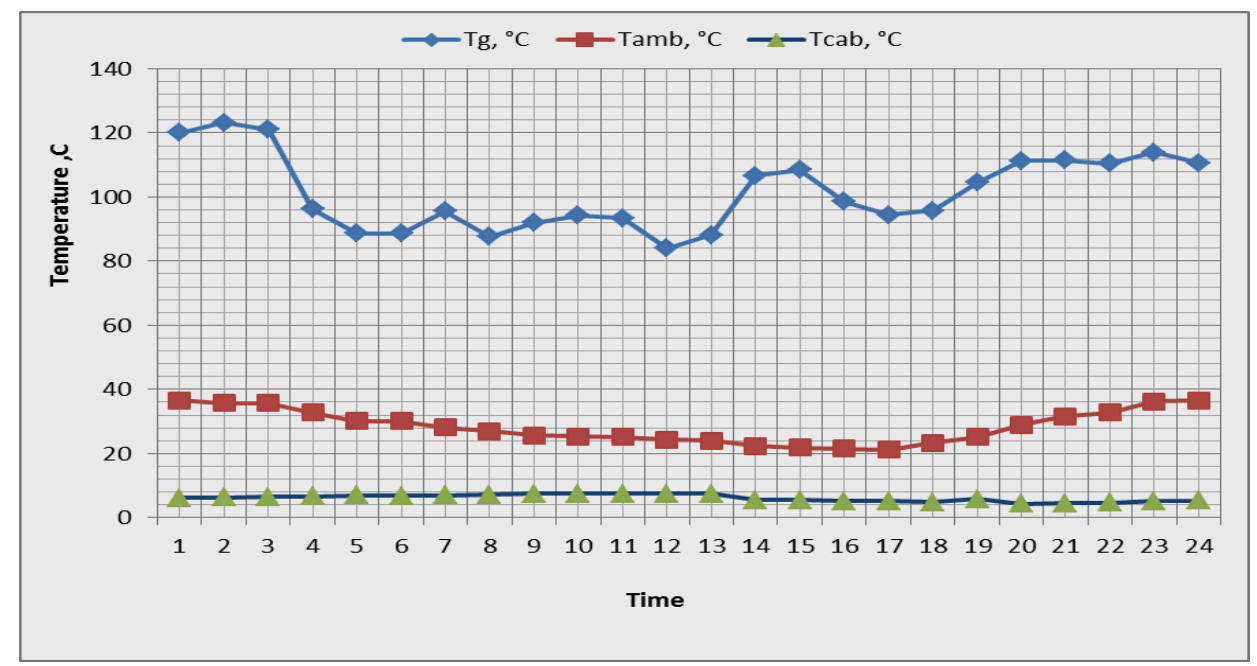

Fig 3: The thermal behavior of the generator temperature $(\mathrm{Tg})$, cabinet temperature (Tcab) with ambient temperature during $24 \mathrm{~h}$ operation 
The increasing of inside temperature for this time was because of increasing natural heating load at this day. The natural heating load depends upon the sol air temperature, outside dry air temperature, absortivity of material surface, solar radiation flux incident on the refrigerator as a vertical surface and convection heat transfer coefficient. The refrigerating unit extraction of the natural heating load the inside temperature decreased, and then increased after sunrise. Also, the hourly average generator temperature had higher values during day time than night time. The previous results revealed due to the higher natural heating load gaining higher generator temperature. The previous data proved that absorption refrigeration system has ability to decrease temperature inside refrigerator unit from potato temperature ranges. Also, the absorption refrigeration system can work under high natural heating load and outside air temperature.

Fig.4 indicates the various values of COP that calculated from temperature thermodynamic, mass flow rate thermodynamic and cooling capacity equations. This figure compared between these values at same conditions, which COP is functioned of their parameters based on the type of equation. The COP which estimated by Carnot equation through the generator, condenser and evaporator temperatures gave the highest values when compared it by other COP equations. Whilst, The COP that calculated by cooling capacity equation gave the lowest values.

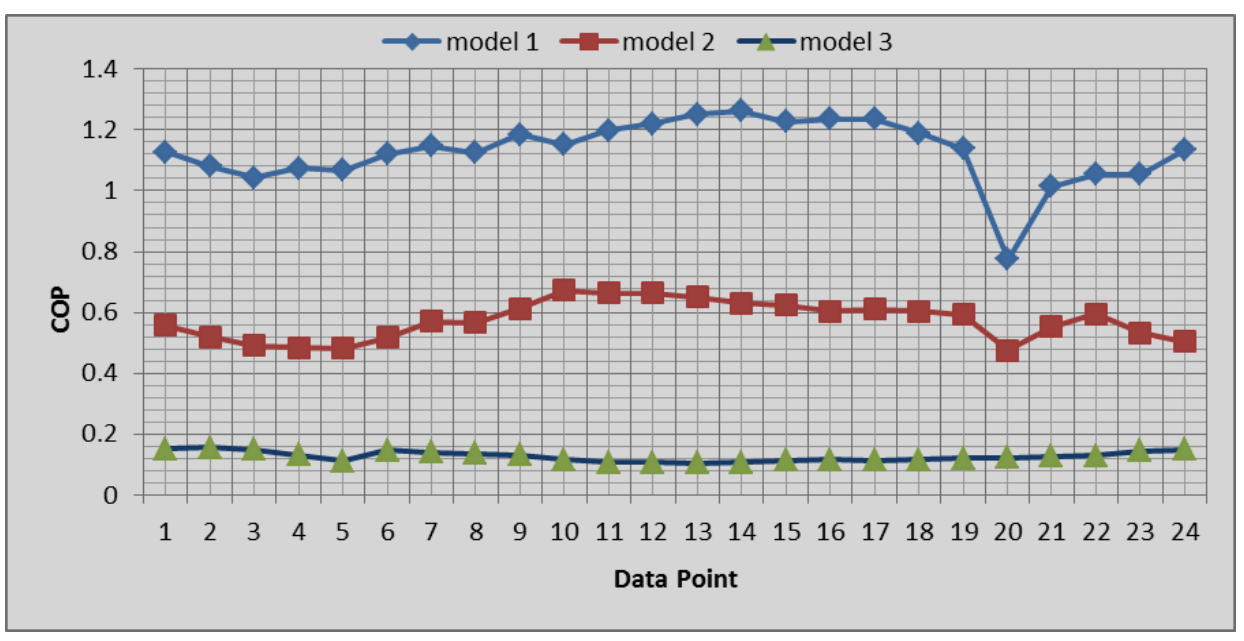

Fig.4: Comparison between different models of COP. 
All the theoretical COP values exceeds 1 except one case, meanwhile COP values were below 1 by other equations. The highest value of COP by temperature thermodynamic was 1.26 while the lowest value was 0.77 . The previous results resulting in generator, condenser and evaporator temperature. Where in lowest case value the condenser temperature neared to $60^{\circ} \mathrm{C}$, this means that the refrigerator cannot eliminate the heat exceeds to the surrounding area caused the reduction of COP below 1 . The COP that calculated by mass flow rate thermodynamic equation gave the medium values when compared it by temperature thermodynamic and cooling capacity equations. These values varied because the COP values based on Carnot equation represented the ideal equation for ideal conditions i.e. theoretical values. Nevertheless, the COP values by other methods were deal with actual conditions. The theoretical equation gave the overview for the behavior of fluids throughout the refrigeration circuit. Mass flow rate represented the actual conditions of working fluids and phase change from part to part of refrigeration cycle. The flow rate of mass rate throughout the refrigeration cycle not only based on temperature and pressure, but also the specifications of refrigeration circuit parts as area and volume. Consequently, the cycle performance by mass flow rates depends upon the energy balance equation this gave an actual results for the refrigeration circuits. The COP using cooling capacity equation contained limited parameters, that gave not the actual or nearby values.

Fig.5 showed the connection between the generator temperature and circulation ratio. The increase generator temperature the decrease circulation ratio. This means that the higher generator temperature causing the resistance of the circulation times of working fluids throughout the refrigeration cycles. The relationship as an exponential function behavior. Which gave the equation: $\mathrm{f}=629.52 \mathrm{e}-0.0193 \mathrm{Tg}$

Fig.6 and Table1. indicated the Pythagorean means which represents the statistical indicators. From these Table and Figure, the values or percentage of these values pointed out to COP by second and third models as a ratio of first model. Consequently, the first model gave the percentage $100 \%$ for different types of COP that represents the standard 
of COP as a benchmark to measure other models. The lowest values indicated by model 3 . The values by model 2 gave the intermediate values among the COP types.

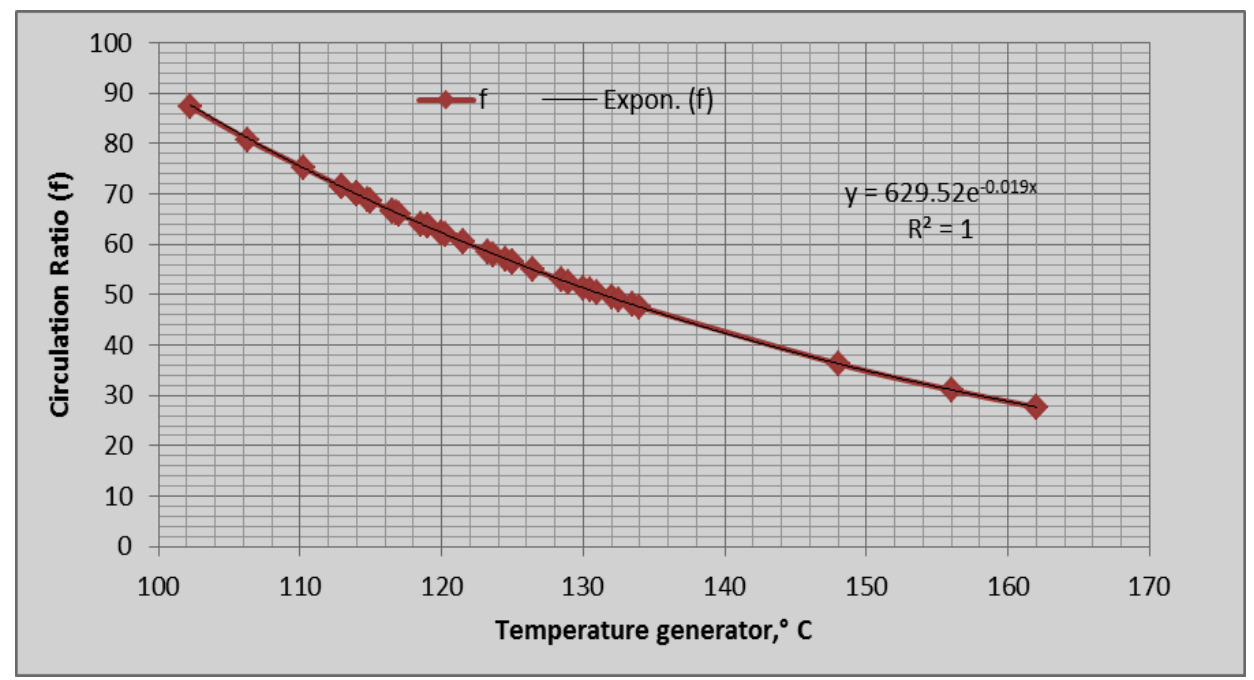

Fig.5. The relation between the circulation ratio and generator temperature.

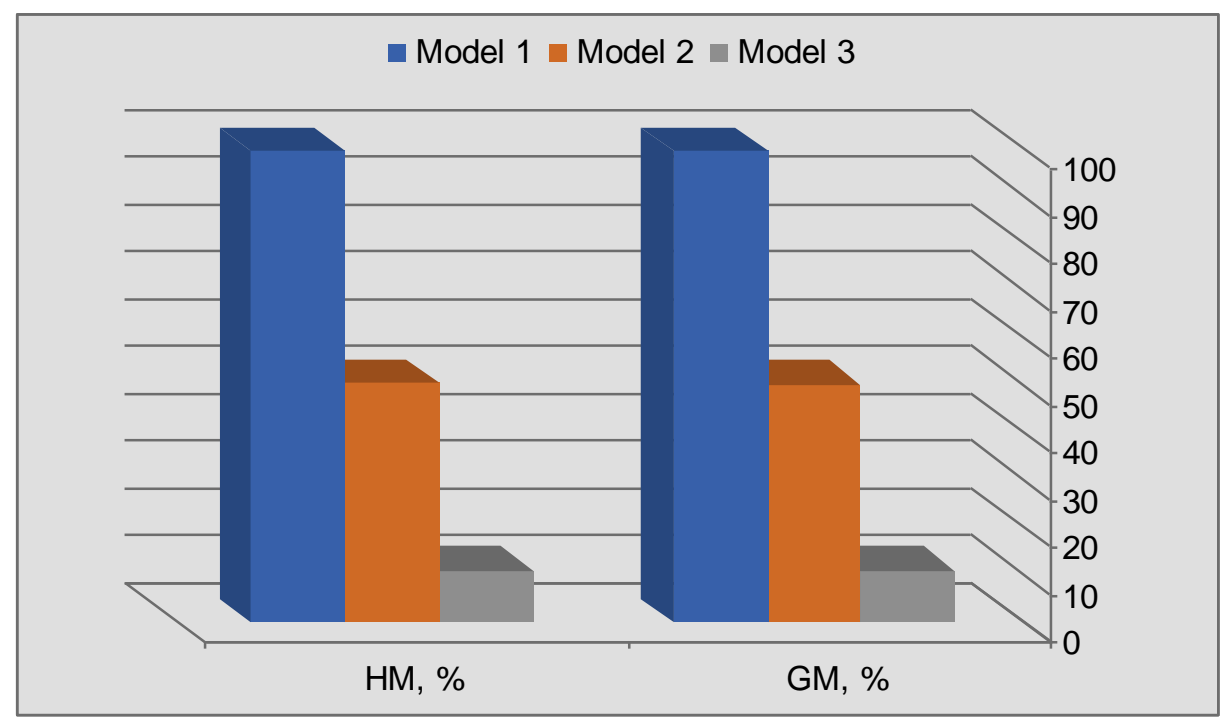

Fig.6. Values of geometric and harmonic means of COP by second and third models as a ratio of model 1 
Table1: The statistical indicators to select the actual COP

\begin{tabular}{|l|l|l|l|}
\hline $\begin{array}{l}\text { COP } \\
\text { Pythagorean }\end{array}$ & COP, Carnot & COP, mass flow rate & COP, cooling capacity \\
\hline HM & 1.1181 & 0.5672 & \\
\hline HM, \% & 100 & 50.72 & 0.1248 \\
\hline GM & 1.1300 & 0.5705 & 11.16 \\
\hline GM, \% & 100 & 50.48 & 0.1258 \\
\hline Average & 1.1294 & 0.5738 & 11.13 \\
\hline Average, \% & 100 & 50.81 & 0.1268 \\
\hline
\end{tabular}

\section{ACKNOWLEDGEMENT}

Deepest thanks to Prof. Dr. Ian Eames in Thermal Power at Nottingham University for their help, throughout my research work.

\section{CONCLUSION}

The coefficient of performance (COP) estimated by three paths. These ways were Carnot cycle, mass flow rate thermodynamic and cooling capacity. These values differ between them when compared by their equations. The calculations showed that the Carnot cycle gave the ideal performance. While, the other methods gave actual values. But, COP values calculated based on mass flow rate were near to real cycle. Because it associated with the moving of working fluids in DAR cycle where each part has specific operating temperature that revealed the thermodynamic properties of working fluids and size of cycle. In addition, the circulation ratio (f) decreased with increased generator temperature.

\section{REFRENCES}

Acuña, A., N. Velàzque, D. Sauceda, P. Rosales, A. Suartegui and A. Ortiz. (2016). Influence of a compared parabolic concentrator in the performance of a solar difusión absorption cooling system. Applied Thermal Engineering, 102: 1374-1383. 
Agostini, B.; F. Agostini and M. Habert. (2016). Modeling of a Von Platen Munters diffusion absorption refrigeration cycle. Journal of physics conference series 745032053

Babu. B. and M. P. Yadav. (2015). Performance of Llithium-Bromide water absorption refrigeration system using waste heat of boiler flue gases. International Journal of Engineering Research and Management (IJERM), 2(2): 42-47

Ben Iffa, R.; N. Bouaziz and L. Kairouani. (2017). Optimization of a absorption refrigeration systems by design of experiments method. Energy procedia, 139:280-287.

Ersoz, M. A. (2015). Investigation the effect of different heat inputs supplied to the generator on the energy performance in diffusion absorption refrigeration systems. International of refrigeration, 145: $10-21$

\section{Darwesh, M.; A. H. Elmetwalli; A. Derbala; T. Fouda and M. Morad.} (2010). Manufacture and performance evaluation of solar absorption unit for potato storage. Misr J. of Agric. Engineering, the 17th Annual Conference of the Misr Society of Agric. Engineering "Role of agricultural engineering in environmental and sustainable development for the valley and Delta areas" Agric. Engi. Dept., Faculty of Agric., Tanta University, 27-28 October, 2010, 27(4):1907-1921.

Kang, Y. T., Y. Kunugi and T. Kashiwiagi. (2000). Review of advanced absorption cycles: performance improvement and temperature lift enhancement. Int. J. Refrig, 23: 388-401.

Kassem, A.; A. Shoker and A. Bassuony. (1993). Performnae of an intermittent absorption solar solar refrigeration. Misr. J. Agric. Eng., 10(2): 267-285

Keçeciler, A. H.; I. Acar and A. Doğ an (2000). Thermodynamic analysis of the absorption refrigeration system with geothermal energy: an experimental study. Energy conversion and management, 41(1): 37-48.

Kumar, M and R. K. Das. (2015). Thermodynamic study of diffusion absorption refrigeration system with organic fluid. International 
Journal of Mechanical Engineering and Robotics Research, 4(1): 473484.

Mansouri, R., S. Mazouz, M. Bourous and A. Bellag. (2015). Experimental study and steady- state modelling of a commercial diffusion absorption refrigerator. Revue des Energies Renouvelables, special ICT $_{\mathrm{s}^{-}}$MENA, BouIsmail, 7-14.

Matta, p., Saikiran., SK. Khaja and A. V. K. Manoj. (2017). Design of vapour absorption refrigeration system of 1.5 TR capacity by waste heat recovery process. International Journal of Pure and Applied Mathematics, 115 (7): 613-619.

Mazouz, S., R. Mansouri and A. Bellagi. (2014). Experimental and thermodynamic investigation of an ammonia/ water diffusion absorption machine. International Journal of Refrigeration, 45:83-91

Mc Carney, S., J. Robertson., J. Arnaud., K. Lorenson and J. Lloyd. (2016). Using solar-powered refrigeration for vaccine storage where other sources of reliable electricity are inadequate or costly. Vaccine, 31(51): 6050-6057.

Mungan, C.E. (2017). Coefficient od performance of Stirling refrigerators. Eur.J.Phys. 38 (9pp).

Najjaran, A.; J. Freeman.; A. Ramos and C. N. Markides. (2017). Experimental performance analysis of an ammonia-water diffusion absorption refrigeration cycle. $13^{\text {th }}$ International Conference on Heat Transfer, Fluid Mechanics and Thermodynamics, pp: 950-955

Rastovski, A. (1987). Storage losses. In: Rastovski, A, Van Es, A. (eds.) Storage of potatoes. Post- harvest behavior, store design, storage practice, handling. Pudoc. Wageningen.

Starace, G. and L. De pascalis . (2013). An enhanced model for the design of diffusion absorption refrigerators. International Journal of refrigeration, 36: 1495-1503.

Srikhirin, P.; S. Aphornratana and S. Chungpaibulpatana. (2001). A review of absorption refrigeration technologies. Renewable and Sustainable Energy Reviwes, 5: 343-372. 
الملخص العربى

إستجابة النماذج الرياضية لحساب معدل الأداء لاوائر التبريد بالامتصاص

\section{د/ محمد درويش' و د/ عاطف السباعي`}

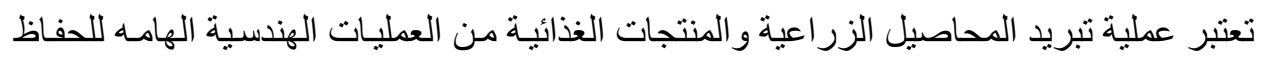

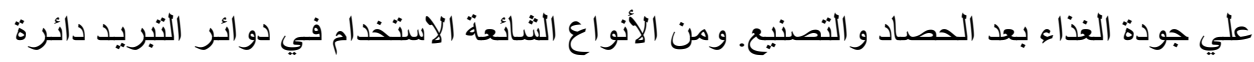

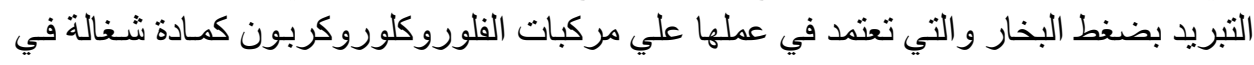
دائرة التبريد.كذللك فإن هذه الدوائر تعتمد في عملها علي الطاقة الكهربائية و التي تعتمد في إنتاجها علي حرق الوقود الأحفوري كطاقة نقليدية.

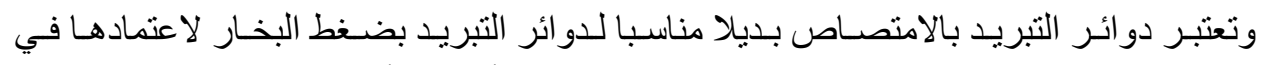

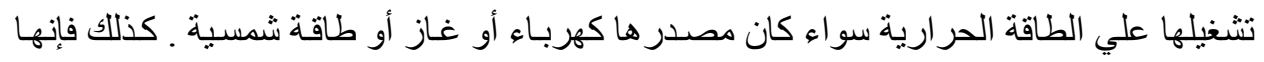

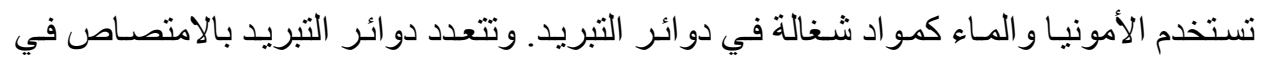

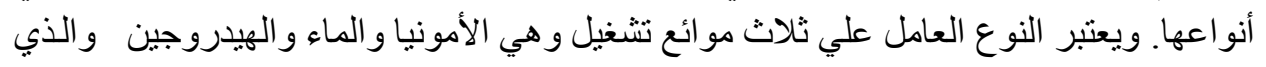

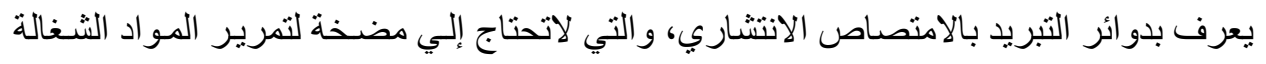

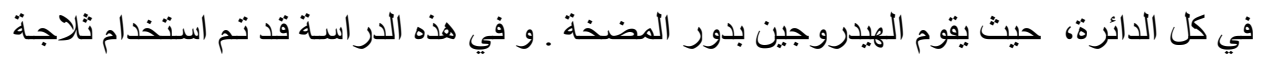

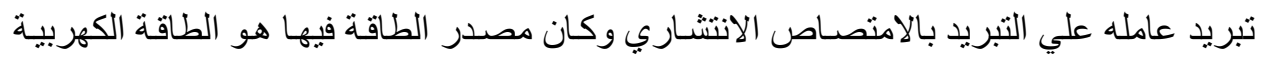

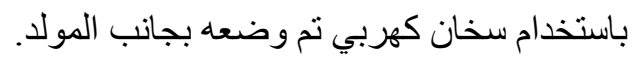

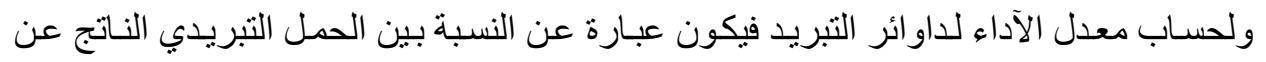

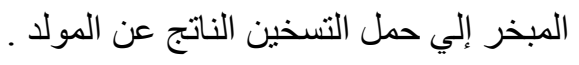



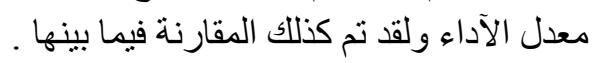
النموذج الرياضي الأول يعتمد علي درجـات الحرارة الخاصــة بـدوائر التبريد فيمـا يعرف بـدائرة كارنوت. النموذج الرياضـي الثاني يعتمد علي الخو اص الثرموديناميكيـة للمو اد الثــالة في دائرة التبريد بالامتصاص كنتيجة في معدل سريان هذه المو اد نتيجة للفرق في درجات الحرارة في أجزاء دورة التبريد. النمـوذج الرياضـي الثالث يعتمـد علـي سـعة التبريـد مـن حيـث كميـة المـادة التي تحتـاج للتبريـد

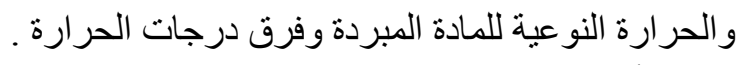

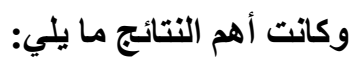

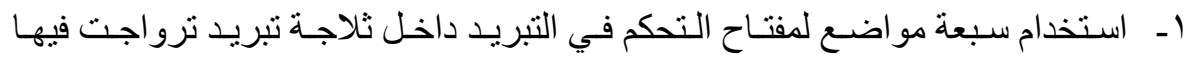

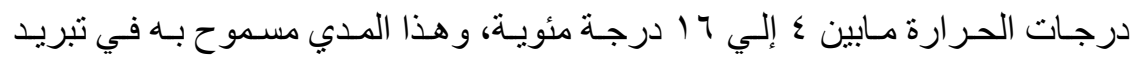

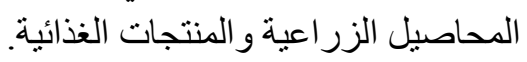

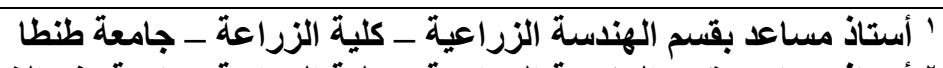

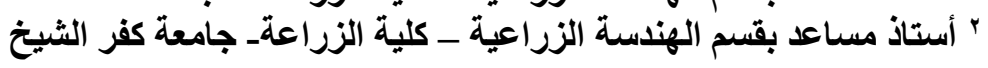




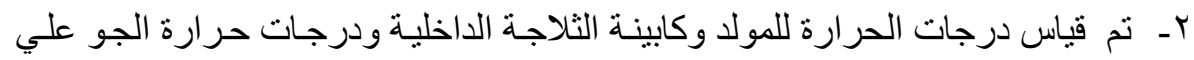

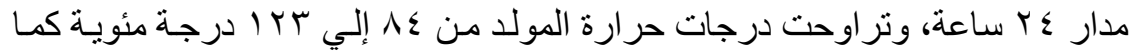

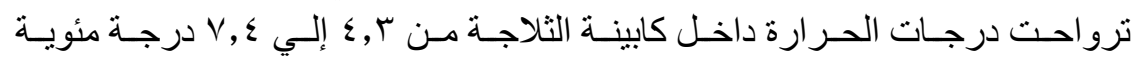
وترواحت درجات الحرارة الداخلية بين اب إلي بـ داخدة درجة مئوية.

تم حساب معدلات الآداء طبقا للنماذج الرياضية الثناث المستخدمة في الدر اسـة، وتر اوحت

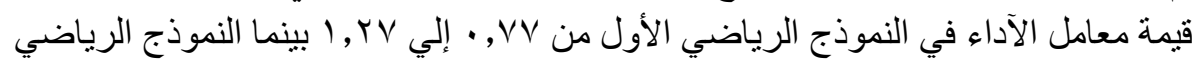

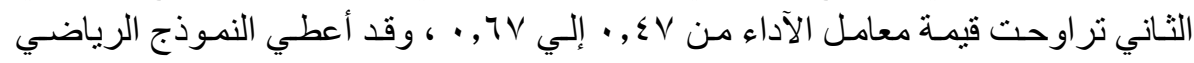

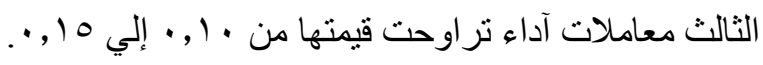

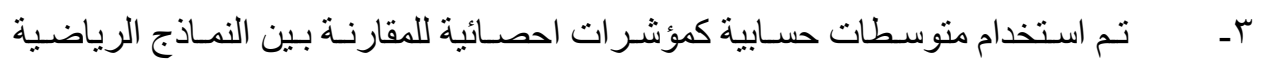

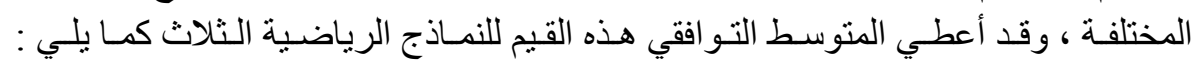

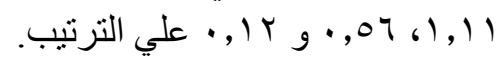

وقد انتهت الدراسة إلي الاعتماد علي النموذج الرياضي الثاني و الذي يعتمد علي الخصـائص

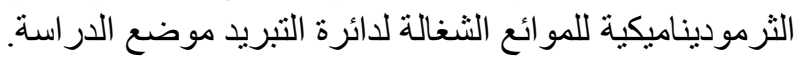

